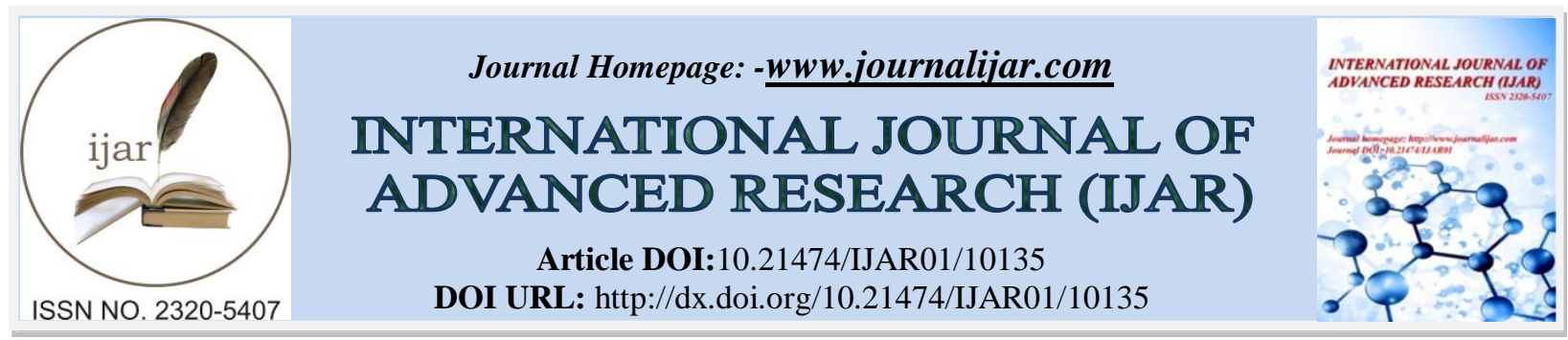

RESEARCH ARTICLE

\title{
A DESCRIPTIVE STUDY TO ASSESS THE KNOWLEDGE OF MOTHERS OF UNDER FIVE CHILDREN REGARDING MANAGEMENT OF DIARRHEA.
}

Ramandeep Kaur ${ }^{1}$ and Ms. Kajal ${ }^{2}$.

1. Tutor, College of Nursing, Government Medical College and Hospital, Chandigarh.

2. Government Medical College and Hospital, Panjab University, Chandigarh.

\section{Manuscript Info}

Manuscript History

Received: 01 October 2019

Final Accepted: 03 November 2019

Published: December 2019

\begin{abstract}
A descriptive study to assess the knowledge of mothers of under five children regarding management of diarrhea in paediatric OPD at Government Medical College and Hospital, Sector-32, Chandigarh.The objectives of the study were to assess the level of knowledge of mothers of children less than five years of age regarding management of diarrhea and to find out association between knowledge score with selected socio demographic variables. A prospective, observational research design was used. Purposive sampling technique was used to select 260 subjects visiting paediatric OPD, Government Medical College and Hospital, Sector-32, Chandigarh. Data obtained from study subjects by Performa's developed by the researchers consisting of Part A - to collect socio-demographic data and Part B - to assess knowledge of mothers of under five children regarding management of diarrhoea. Data analysis was done by calculating mean, percentage and correlation coefficient by using descriptive and inferential statistics at $\mathrm{p}<0.05$ was considered statistically significance. The study concluded that majority of the mothers of under five children had average knowledge regarding management of diarrhea. There was association between knowledge score and marital status. The findings of the study reveal that out of 260 subjects, $23 \%$ had good knowledge, $73 \%$ had average knowledge and $4 \%$ had poor knowledge regarding management of diarrhea in under five children.
\end{abstract}

Copy Right, IJAR, 2019,. All rights reserved.

\section{Introduction:-}

Diarrhea is one of the most common manifestations of illness in infants and children. It is characterized by an increased in fluidity, frequency, volume as well as possible changes in colour of faces in comparison with the usual stool pattern of the individual. The usual stool pattern of breast-fed infants may be several stools a day, whereas formula fed infants may be one stool every other day. Diarrhea is a symptom of variety of conditions, and it constitutes one of the main causes of morbidity and mortality among infants and children throughout the world. ${ }^{1}$

Diarrhea is usually defined as passage of 3 or more loose watery stool in a 24-hour period, loose stool being one that would take the shape of a container. Diarrhea is one of the most common ailments in young children. A recent change in the consistency or character of stool is more important than the number of stools. ${ }^{2}$

Corresponding Author:-Ramandeep Kaur.

Address:- Tutor, College of Nursing, Government Medical College and Hospital, Chandigarh. 
In India diarrheal disease is a major public health problem among children under the age of 5 years. Diarrhea kills nearly 5 lakhs children a year in India. ${ }^{3}$

Studies in the literature show that though most of the mothers were familiar with the term oral rehydration salt (ORS), there were knowledge gaps as regards its correct preparation and administration. The signs of dehydration due to diarrhea remain unnoticed by the majority of the mothers. There are certain fluids which are beneficial to give during diarrhea. Mothers' knowledge about diarrhea can be improved through Health education. ${ }^{5}$

\section{Need of the study:-}

According to UNICEF Diarrhea is a leading killer of children, accounting for approximately 8 per cent of all deaths among children under age 5 worldwide in 2016. This translates to over 1,200 young children dying each day, or about 450,000 children a year, despite the availability of simple effective treatment. ${ }^{4}$

Diarrhea is common among children and contributes substantially to pediatric morbidity and mortality worldwide. Diarrhea is a major public health problem in developing countries like India. An estimated 1.8 Billion episodes of diarrhea occurs in each year and 3 million children under the age of 5 years die due to diarrhea. ${ }^{5}$

Many of the children who were suffering from diarrhea, gastro intestinal disturbances due to various reasons and they were not given proper care and treatment and were neglected by mothers due to their limited knowledge on diarrhea and its management. This incidence provoked us to do something needful for the community, particularly towards preventing and managing diarrhea in children. So, this study was taken up as the research topic of concern. ${ }^{5}$

\section{Statement of problem:-}

A descriptive study to assess the knowledge of mothers of under five children regarding management of diarrhea in pediatric OPD at Government Medical College and Hospital, Sector or 32, Chandigarh.

\section{Objectives:-}

1. To assess the level of knowledge of mothers of children less than five years of age.

2. To find the association between level of knowledge and selected socio-demographic variables.

\section{Hypothesis:-}

$\mathbf{H}_{\mathbf{0}}$ (Null hypothesis): There is no statistically significant association of knowledge of mothers of under five children with selected demographic variable at $\mathrm{p}<0.05$ level.

$\mathbf{H}_{1}$ (Research hypothesis): There is statistically significant association of knowledge of mothers of under five children with selected demographic variable at $\mathrm{p}<0.05$ level.

\section{Delimitation:-}

The study was delimited to the mothers or caregivers of under-five children visiting to pediatric OPD- GMCH, Chandigarh, whose knowledge was assessed through self-structured questionnaire.

\section{Material and Methods:-}

Quantitative research approach was selected as the study was designed to assess the knowledge of mothers regarding management of diarrhea. A Descriptive cross-sectional study design was used to utilize the objectives. The study was conducted in pediatrics OPD, Government Medical College and Hospital, sector 32, Chandigarh. Target population was mothers of under five children visiting paediatric OPD, GMCH-32, Chandigarh. Convenient sampling technique was used to select the available samples from the target population. Sample size was calculated and 260 mothers were taken. Mothers who were willing to participate and who can understand Hindi/English/Punjabi were included in the study.

Permission of conducting research study was taken from ethical and research committee of Government Medical College and Hospital, sector 32, Chandigarh. Permission was taken from head of the department of paediatrics and respective ward in-charges. Written informed consent from the mothers was taken. Confidentiality and anonymity of samples was maintained. 
Tool was constructed and verified to collect data from the samples .it had 2 parts namely

1. Part A- Questionnaire related to socio-demographic profile

2. Part B- Questionnaire related to assess the knowledge regarding management of diarrhea among mothers of under five children Consent was taken from each mother for collection of data.

Data analysis was done in an agreement with the objectives of the study. Data analysis was done by using the descriptive and inferential statistics. The level of significance was selected at $\mathrm{p}<0.05$. Data analysis was done by calculating mean, percentage, and by using chi-square test and one-way ANOVA.

\section{Results and Findings:-}

Findings related to socio-demographic profile

Most of the mothers were in age group of 20-30 years. Out of 260 subjects $70.8 \%$ belong to Hindu religion, $25 \%$ to Sikh religion and remaining to other religions. Out of all subjects $97.7 \%$ mothers were married, $0.8 \%$ was widow and $0.4 \%$ was separated. Majority of the subjects i.e., $98.5 \%$ were the biological mothers of their child and $1.5 \%$ were their guardian. According to their educational status, $43.8 \%$ were graduate, $4.6 \%$ were illiterate, and $8.1 \%$ and $17.7 \%$ have done their education upto secondary and senior secondary level respectively and $25.8 \%$ were postgraduates. Out of 260 subjects, $81.9 \%$ were homemakers, $12.7 \%$ were self employed and $5.4 \%$ were in service either private or government. No subject was from slum area, $35.4 \%$ were from rural residential area and $64.6 \%$ were from urban areas. The family incomes of more than 50\% subjects were between rupees 5000-50000. Out of total subjects, $46.5 \%$ have one child, $43.8 \%$ have two children and only $9.6 \%$ have three or more than three children. Majority of the subjects i.e., $85 \%$ have only one child of under five age group.

Findings related to level of knowledge of mothers regarding management of diarrhea in children less than five years of age.

Tab. 1:-Percentage distribution of knowledge of mothers regarding management of diarrhea in children less than five years of age. $\mathbf{N}=\mathbf{2 6 0}$

\begin{tabular}{|l|l|l|l|l|}
\hline Knowledge & $\mathbf{n}$ & $\mathbf{\%}$ & $\boldsymbol{\mu}$ & SD \\
\hline Poor & 10 & 3.8 & 13.32 & 3.13 \\
\hline Average & 189 & 72.7 & & \\
\hline Good & 61 & 23.5 & & \\
\hline Total & 260 & 100.0 & & \\
\hline
\end{tabular}

Overall score -22

Table 1 depicts the frequency and percentage distribution of level of knowledge among mothers about management of diarrhea in children less than five years of age. Out of 260 mothers, 10 scored below 07 out of 22 marks i.e., they had poor knowledge; 189 scored between 8-15 out of 22 marks i.e., they had average knowledge; 61 scored above 16 out of 22 marks i.e., they had good knowledge regarding management of diarrhea.

Findings related to association between socio-demographic variables and level of knowledge

It was found that the subjects who were married and live with their husbands have scored higher than those who were separated, single, divorced or widowed. A significant association was found between the marital status of subjects with the knowledge score as p-value comes out to be 0.019 .

\section{Discussion:-}

Findings of the study show that mothers of under five children had average knowledge regarding management of diarrhea. Overall knowledge score of mothers of under five children is out of 260 subjects $23 \%$ of total subjects had good knowledge, $73 \%$ had average knowledge and $4 \%$ had poor knowledge regarding management of diarrhea.In our study, association of selected socio demographic variables with knowledge score has significant association with marital status of subjects as $\mathrm{p}=0.019<0.05$. The present study is supported by a study in which it was found that among 60 samples, 55\% mothers of under five children have inadequate knowledge, 36.6\% mothers of under five children have moderate knowledge and $8.3 \%$ mothers of under five children have adequate knowledge regarding home management of diarrhea. A significant association was found between the socio-economic status and the level of knowledge among mothers of under five children. According to WHO diarrhea is one of the leading causes of 
child morbidity and mortality worldwide. Taking into consideration, major initiatives were taken by Indian government regarding diarrheal management such as Diarrheal Control Programme (1978), Oral Rehydration Therapy, Zinc supplementation, $\mathrm{RCH}$ and $\mathrm{MCH}$ programme Immunization, health education and sanitation.Community participation; proper health education in the remote, backward and rural areas; and increased awareness among community had filled the gaps of knowledge regarding management of diarrhea among mothers of higher and lower socio-economic groups.

\section{Conclusion:-}

The study concluded that majority of the mothers of under five children had average knowledge regarding management of diarrhea. There was association between knowledge score and marital status. The findings of the study reveal that out of 260 subjects, $23.5 \%$ had good knowledge, $72.7 \%$ had average knowledge and $3.8 \%$ had poor knowledge regarding management of diarrhea in under-five children.

\section{Acknowledgements:-}

Authors are thankful to the management of GMCH, Chandigarh

\section{References:-}

1. Dorothy R,Barbara A .The Text Book of Pediatric Nursing. Saunders publication $6^{\text {th }}$ edition ; 2002.

2. Dutta P. Pediatric Nursing. Jaypee brothers $2^{\text {nd }}$ edition; 2009:294-8.

3. Kelly P, Khanfir H, David PH, Arata M. Environmental and behavioral risk factors for diarrheal disease in Morocco; Environmental health project. 2013;89;95-9.

4. Shah MS, Ahmad A, Khalique N. Home based management of acute diarrhea disease in Aligarh, a descriptive study, J Infect Dew Ctries 2012;6(2):137-42.

5. Datta V,JohnR,Singh VP. Maternal knowledge, attitude and practices towards diarrhea and oral rehydration therapy in rural Maharashtra, a cross sectional study,Indian J Pediatr 2001;68(11):1035-7. 